\title{
Renal injury is associated with operative mortality after cardiac surgery for women and men
}

\author{
Nanhi Mitter, MD, , Ashish Shah, MD, ${ }^{\mathrm{b}}$ David Yuh, MD, ${ }^{\mathrm{b}}$ Jeffery Dodd-O, MD, ${ }^{\mathrm{a}}$ \\ Richard E. Thompson, $\mathrm{PhD},{ }^{\mathrm{c}}$ Duke Cameron, $\mathrm{MD},{ }^{\mathrm{b}}$ and Charles W. Hogue, $\mathrm{MD}^{\mathrm{a}}$
}

\begin{abstract}
Objectives: The purpose of this study was to determine whether acute renal injury develops more frequently in women than in men after cardiac surgery and whether this complication is associated with operative mortality in
\end{abstract} women.

\begin{abstract}
Methods: Prospectively collected data were evaluated from 9461 patients undergoing coronary artery bypass graft surgery, cardiac valve surgery, or both (3080 women) and not receiving preoperative dialysis. The glomerular filtration rate was estimated by using the Modification of Diet in Renal Disease equations with the last plasma creatinine level before surgical intervention (baseline) and the highest level of the first postoperative week. The primary renal injury outcome was the composite end point of renal injury according to RIFLE criteria (estimated glomerular filtration rate decrease $>50 \%$ from baseline value) or failure.
\end{abstract}

Results: Thirty-day operative mortality and renal injury were more common in women than in men $(5.9 \%$ vs $2.8 \%, P=.01 ; 5.1 \%$ vs $3.6 \%, P<.001$, respectively). Nonetheless, patient sex was not independently associated with risk for renal injury when the baseline estimated glomerular filtration rate was included in multivariate modeling. Perioperative complications, intensive care unit length of stay, and mortality were more frequent for patients with than without renal injury (women, $20.6 \%$ vs $3.2 \%, P<.0001$; men, $18.3 \%$ vs $2.2 \%, P<.001$ ). Renal injury was independently associated with 30-day mortality for women (odds ratio, 3.96; 95\% confidence interval, 1.86-8.44; $P<.0001$ ) and men (odds ratio, 4.05; 95\% confidence interval, $2.19-7.48 ; P<.0001$ ).

Conclusions: Postoperative renal injury is independently associated with 30-day mortality regardless of patient sex. Higher rates of renal injury in women compared with men might be explained in part by a higher prevalence of low estimated glomerular filtration rate before surgical intervention. ( $J$ Thorac Cardiovasc Surg 2010;140:1367-73)

Women are at higher risk for mortality after cardiac surgery than are men, but an explanation for this higher risk is not completely clear. ${ }^{1}$ Understanding the sex-specific causes of operative mortality is fundamental for developing preventative strategies. Acute renal failure develops in $5 \%$ to $30 \%$ of patients after cardiac surgery when cardiopulmonary bypass (CPB) is used, predisposing affected patients to in-hospital and long-term mortality. ${ }^{2-6}$ Even small increases in serum creatinine levels $(0.5 \mathrm{mg} / \mathrm{dL})$ after surgical intervention are associated with high mortality, longer length of hospitalization, and higher hospital costs. ${ }^{4,6}$ Female sex has been identified as an independent risk factor for postoperative renal failure, although it has not been a consistent finding. ${ }^{2,5-7}$ Notably, investigators who have

\footnotetext{
From the Department of Anesthesiology and Critical Care Medicine ${ }^{\mathrm{a}}$; the Division of Cardiac Surgery, ${ }^{\mathrm{b}}$ Department of Surgery; and the Bloomberg School of Public Health, ${ }^{c}$ the Johns Hopkins Medical Institutions, Baltimore, Md.

Supported in part by grant 64600 from the National Institutes of Health (to C.W.H.). Disclosures: None.

Received for publication March 9, 2009; revisions received Dec 1, 2009; accepted for publication Feb 8, 2010; available ahead of print April 12, 2010.

Address for reprints: Charles W. Hogue, MD, Department of Anesthesiology and Critical Care Medicine, the Johns Hopkins Hospital, 600 N Wolfe St, Tower 711, Baltimore, MD 21287 (E-mail: chogue2@jhmi.edu). $0022-5223 / \$ 36.00$

Copyright $(c) 2010$ by The American Association for Thoracic Surgery doi:10.1016/j.jtcvs.2010.02.021
}

evaluated the role of postoperative renal dysfunction in patient outcomes have not separately considered the effect of female sex. ${ }^{2-6}$ This omission is important because women represented a minority $(<30 \%)$ of patients in these studies, and the small number might limit extrapolation of data derived predominately from men. Furthermore, compared with men, women usually have less muscle mass and are typically older at the time of surgical intervention; both of these factors could affect the levels of serum creatinine. ${ }^{1,8}$ Thus the purpose of this study was to evaluate whether acute renal injury that develops after cardiac surgery is more common in women than in men and whether it is associated with operative mortality in women.

\section{MATERIALS AND METHODS \\ Study Design and Patient Population}

All study procedures were approved by the institutional review board of the Johns Hopkins Medical Institutions, and each patient provided written informed consent for data collection and analysis before surgical intervention. Data were prospectively collected by trained abstractors from an electronic medical records system at the Johns Hopkins Hospital as part of data collection for the Society of Thoracic Surgeons (STS) National Cardiac Surgery Database. ${ }^{9}$ Data collected included inpatient medical records, review of outpatient records, letter mailings, and telephone interviews. Patients receiving preoperative dialysis were excluded from the study. We identified 9461 consecutive patients ( $\geq 30$ years old) who had undergone coronary 


\author{
Abbreviations and Acronyms \\ $\mathrm{CABG}=$ coronary artery bypass grafting \\ $\mathrm{CPB}=$ cardiopulmonary bypass \\ eGFR = estimated glomerular filtration rate \\ RIFLE $=$ Risk, Injury, Failure, Loss, and End-Stage \\ Kidney Disease \\ STS $=$ Society of Thoracic Surgeons
}

\section{RESULTS}

Patient characteristics for the 9150 survivors and the 311 patients who experienced operative mortality are listed in Table 1 according to patient sex. Operative mortality was higher for women than for men $(4.2 \%$ vs $3.0 \%$, $P=.001)$. Compared with survivors, women and men who died were older and were more likely than surviving patients of the same sex to have low eGFRs before surgical intervention. Other differences between survivors and nonsurvivors for each sex are noted in Table 1. Comparisons of the frequency of variables that differed between nonsurviving women and men are listed in Table 1 . For the most part, variables associated with mortality were similar between women and men, with a few exceptions. Compared with nonsurviving men, women who experienced operative mortality had a higher frequency of diabetes, left ventricular ejection fraction of less than $50 \%$, hypercholesterolemia, hypertension, prior myocardial infarction, and current smoking. Nonsurviving women had a lower frequency of triplevessel coronary artery disease than did nonsurviving men. Differences in the type of operation between female and male nonsurvivors were noted.

Baseline eGFR, the frequency of different levels of reduced eGFR, and the distribution of RIFLE criteria for renal injury by patient sex are listed in Table 2 . Women had a lower eGFR before surgical intervention than did men, and higher frequencies of women had eGFRs of less than $30 \mathrm{~mL} / \mathrm{min}$ per $1.73 \mathrm{~m}^{2}$ of body surface area and eGFRs of 30 to $60 \mathrm{~mL} / \mathrm{min}$ per $1.73 \mathrm{~m}^{2}$ of body surface area. Forty-four women and 33 men were reported to have new dialysis after surgical intervention but were not listed as having renal injury or failure based on the RIFLE criteria (because of dialysis correction of serum creatinine levels); these patients were included in the renal injury outcome. The primary renal injury outcome occurred in $5.1 \%$ of women and $3.6 \%$ of men $(P<.001)$. The $\chi^{2}$ value for each category is provided in Table 2 and shows that most of the weighting for the combined $P$ value was from the RIFLE categories of "risk" or "injury," suggesting that these 2 categories drive the statistical association between sex and RIFLE criteria.

Characteristics for surviving and nonsurviving patients with and without renal injury for each sex are listed in Table 3. Although many univariate predictors of mortality for patients with renal injury were similar for women and men, differences were noted. As in Table 1, the frequency of variables that differed between survivors and nonsurvivors for each sex are listed, and comparisons between nonsurviving women and men are provided for these variables. In contrast to nonsurviving men, women with renal injury who died had a higher frequency of left ventricular ejection fraction of less than $30 \%$, hypercholesterolemia, hypertension, triplevessel coronary artery disease, and significant left main coronary stenosis. Nonsurviving women with renal injury had 
TABLE 1. Patient characteristics of survivors and nonsurvivors based on patient sex

\begin{tabular}{|c|c|c|c|c|c|c|c|c|c|}
\hline Clinical characteristic & $\begin{array}{c}\text { Female } \\
\text { survivors } \\
(\mathbf{n}=\mathbf{2 9 5 1}) \\
\end{array}$ & $\begin{array}{c}\text { Female } \\
\text { nonsurvivors } \\
(\mathbf{n}=\mathbf{1 2 9}) \\
\end{array}$ & $\begin{array}{c}\text { Frequency of } \\
\text { variable for } \\
\text { nonsurvivors }\end{array}$ & $\begin{array}{c}P \\
\text { value* }^{*}\end{array}$ & $\begin{array}{c}\text { Male } \\
\text { survivors } \\
(\mathrm{n}=6 \mathbf{6 1 9 9}) \\
\end{array}$ & $\begin{array}{c}\text { Male } \\
\text { nonsurvivors } \\
(\mathbf{n}=\mathbf{1 8 2}) \\
\end{array}$ & $\begin{array}{c}\text { Frequency of } \\
\text { variable for } \\
\text { nonsurvivors }\end{array}$ & $\begin{array}{c}P \\
\text { value* }^{*}\end{array}$ & $\begin{array}{c}\boldsymbol{P} \\
\text { value } \dagger\end{array}$ \\
\hline Mean \pm SD age $(y)$ & $65.9 \pm 12.3$ & $71.4 \pm 11.5$ & & .0001 & $63.6 \pm 11.7$ & $70.0 \pm 11.5$ & & .0001 & .8543 \\
\hline African American & $492(16.7 \%)$ & $23(17.8 \%)$ & $4.5 \%$ & .730 & $603(9.7 \%)$ & $17(9.3 \%)$ & $2.7 \%$ & .862 & .0117 \\
\hline $\begin{array}{l}\text { Mean } \pm \text { SD body } \\
\text { surface area }\left(\mathrm{m}^{2}\right)\end{array}$ & $1.80 \pm 0.23$ & $1.77 \pm 0.23$ & & .1365 & $2.05 \pm 0.22$ & $1.97 \pm 0.24$ & & .0001 & $\leq .0001$ \\
\hline Chronic lung disease & $327(11.1 \%)$ & $16(12.4 \%)$ & $4.7 \%$ & 640 & $532(8.6 \%)$ & $33(18.1 \%)$ & $5.8 \%$ & $\leq .0001$ & .447 \\
\hline Diabetes & $917(31.1 \%)$ & $49(38.0 \%)$ & $5.1 \%$ & .098 & $1553(25.0 \%)$ & $53(29.1 \%)$ & $3.3 \%$ & .213 & .026 \\
\hline Left ventricular $\mathrm{EF}<50 \%$ & $1489(50.5 \%)$ & $92(71.3 \%)$ & $5.8 \%$ & $\leq .0001$ & $3578(57.7 \%)$ & $123(67.6 \%)$ & $3.3 \%$ & .008 & $\leq .0001$ \\
\hline Left ventricular $\mathrm{EF}<30 \%$ & $334(11.3 \%)$ & $28(21.7 \%)$ & $7.7 \%$ & $\leq .0001$ & $856(13.8 \%)$ & $56(30.8 \%)$ & $6.1 \%$ & $\leq .0001$ & .301 \\
\hline Reoperation & $119(4.0 \%)$ & $13(10.1 \%)$ & $9.8 \%$ & .001 & $165(2.7 \%)$ & $15(8.2 \%)$ & $8.3 \%$ & $\leq .0001$ & .644 \\
\hline Hypercholesterolemia & $1560(52.9 \%)$ & $61(47.3 \%)$ & $3.8 \%$ & .214 & $3474(56.0 \%)$ & $75(41.2 \%)$ & $2.1 \%$ & $\leq .0001$ & .001 \\
\hline \multicolumn{10}{|l|}{ Preoperative eGFR } \\
\hline$<30 \mathrm{~mL} / \mathrm{min}$ per $1.73 \mathrm{~m}^{2}$ & $133(4.5 \%)$ & $17(13.2 \%)$ & $11.3 \%$ & & $144(2.3 \%)$ & $16(8.8 \%)$ & $10.0 \%$ & & .704 \\
\hline $30-60 \mathrm{~mL} / \mathrm{min}$ per $1.73 \mathrm{~m}^{2}$ & $708(24.0 \%)$ & $50(38.8 \%)$ & $6.6 \%$ & $\leq .0001$ & $971(15.7 \%)$ & $51(28.0 \%)$ & $5.0 \%$ & $\leq .0001$ & .148 \\
\hline$>60 \mathrm{~mL} / \mathrm{min}$ per $1.73 \mathrm{~m}^{2}$ & $2110(71.5 \%)$ & $62(48.1 \%)$ & $2.9 \%$ & & $5084(82.0 \%)$ & $115(63.2 \%)$ & $2.2 \%$ & & .100 \\
\hline Hypertension & $1997(67.7 \%)$ & $92(71.3 \%)$ & $4.4 \%$ & .386 & $3982(64.2 \%)$ & $120(65.9 \%)$ & $2.9 \%$ & .638 & .002 \\
\hline \multicolumn{10}{|l|}{ IABP } \\
\hline Preoperative & $47(1.5 \%)$ & $24(18.6 \%)$ & $10.1 \%$ & & $96(1.5 \%)$ & $29(15.9 \%)$ & $8.7 \%$ & & .636 \\
\hline Intraoperative & $9(0.3 \%)$ & $6(4.7 \%)$ & $33.8 \%$ & $\leq .0001$ & $14(0.2 \%)$ & $4(2.2 \%)$ & $23.2 \%$ & $\leq .0001$ & .108 \\
\hline Postoperative & $124(4.2 \%)$ & $14(10.9 \%)$ & $40.0 \%$ & & $231(3.7 \%)$ & $22(12.1 \%)$ & $22.2 \%$ & & .448 \\
\hline MI & $1194(40.5 \%)$ & $70(54.3 \%)$ & $5.5 \%$ & .002 & $2849(46.0 \%)$ & $94(51.6 \%)$ & $3.2 \%$ & .129 & $\leq .0001$ \\
\hline Emergency PCI & $59(1.9 \%)$ & $1(0.8 \%)$ & $1.7 \%$ & .340 & $111(1.8 \%)$ & $4(2.2 \%)$ & $3.5 \%$ & .768 & .662 \\
\hline Peripheral vascular disease & $449(15.2 \%)$ & $25(19.4 \%)$ & $5.3 \%$ & .212 & $740(11.9 \%)$ & $39(21.4 \%)$ & $5.0 \%$ & $\leq .0001$ & .835 \\
\hline Cerebral vascular disease & $381(12.9 \%)$ & $23(17.8 \%)$ & $5.7 \%$ & .110 & $599(9.7 \%)$ & $34(18.7 \%)$ & $5.4 \%$ & $\leq .0001$ & .825 \\
\hline Cardiac shock & $17(0.6 \%)$ & $4(3.1 \%)$ & $19.0 \%$ & .010 & $39(0.6 \%)$ & $4(2.2 \%)$ & $9.3 \%$ & .033 & .422 \\
\hline Current smoking & $380(12.9 \%)$ & $15(11.6 \%)$ & $3.8 \%$ & .788 & $827(13.3 \%)$ & $15(8.2 \%)$ & $1.8 \%$ & .045 & .032 \\
\hline Triple-vessel CAD & $1253(42.5 \%)$ & $59(45.8 \%)$ & $4.5 \%$ & .659 & $3531(57.0 \%)$ & $87(47.8 \%)$ & $2.4 \%$ & .118 & $\leq .0001$ \\
\hline $\begin{array}{l}\text { Left main } \\
\quad \text { stenosis }>50 \%\end{array}$ & $259(8.8 \%)$ & $14(10.8 \%$ & $5.1 \%$ & .525 & $607(9.8 \%)$ & $17(9.3 \%)$ & $2.7 \%$ & .895 & .070 \\
\hline \multicolumn{10}{|l|}{ Type of operation } \\
\hline \multicolumn{10}{|l|}{ CABG only } \\
\hline With CPB & $1984(67.2 \%)$ & $90(69.8 \%)$ & $4.4 \%$ & .833 & $4808(77.6 \%)$ & $132(72.5 \%)$ & $2.7 \%$ & .144 & $\leq .0001$ \\
\hline Without CPB & $96(3.3 \%)$ & $4(3.1 \%)$ & $4.0 \%$ & & $214(3.4 \%)$ & $5(2.7 \%)$ & $2.3 \%$ & & .469 \\
\hline \multicolumn{10}{|l|}{ AVR } \\
\hline Repair & $120(4 . \% 1)$ & $3(2.3 \%)$ & $2.4 \%$ & .046 & $304(4.9 \%)$ & $7(3.8 \%)$ & $2 \%$ & .001 & 1.00 \\
\hline Replacement & $588(19.9 \%)$ & $37(28.7 \%)$ & $5.9 \%$ & & $981(15.8 \%)$ & $48(26.4 \%)$ & $4.7 \%$ & & .262 \\
\hline \multicolumn{10}{|l|}{ MVR } \\
\hline Repair & $151(5.1 \%)$ & $5(3.9 \%)$ & $3.2 \%$ & .705 & $256(4.1 \%)$ & $8(4.4 \%)$ & $3.0 \%$ & .002 & 1.00 \\
\hline Replacement & $486(16.5 \%)$ & $24(18.6 \%)$ & $4.7 \%$ & & $357(5.8 \%)$ & $22(12.1 \%)$ & $5.8 \%$ & & .464 \\
\hline CABG/AVR & $247(8.4)$ & $12(9.3 \%)$ & $8.5 \%$ & $\leq .0001$ & $482(7.8 \%)$ & $27(14.8 \%)$ & $5.3 \%$ & .001 & .082 \\
\hline CABG/MVR & $175(5.9 \%)$ & $9(7.0 \%)$ & $4.9 \%$ & .645 & $210(3.4 \%)$ & $16(8.8 \%)$ & $7.1 \%$ & $\leq .0001$ & .357 \\
\hline $\begin{array}{l}\text { Duration of aortic } \\
\text { crossclamp (min) } \ddagger\end{array}$ & $72(55-96)$ & $81(60-111)$ & & .0331 & $75(58-98)$ & $83(56-124)$ & & .0334 & .692 \\
\hline Duration of CPB $(\mathrm{min}) \ddagger$ & $109(86-139)$ & $139(99-173)$ & & .0001 & $111(89-138)$ & $136(100-189)$ & & .0001 & .974 \\
\hline
\end{tabular}

Values are reported as number of patients, with percentages in parentheses for the variable for each column of survivor or nonsurvivors. A separate column of percentages lists the frequency of the variable for nonsurvivors for each sex. $S D$, Standard deviation; $E F$, ejection fraction; $e G F R$, estimated glomerular filtration rate; $I A B P$, intra-aortic balloon pump; $M I$, myocardial infarction; $P C I$, percutaneous coronary artery intervention; $C A D$, coronary artery disease; $C A B G$, coronary artery bypass graft; $C P B$, cardiopulmonary bypass; $A V R$, aortic valve replacement; $M V R$, mitral valve replacement. $* P$ value for comparison between survivors and nonsurvivors of the same sex. $\dagger P$ value for comparison of the distribution of the variable between women and men. $\ddagger$ Values are reported as medians (interquartile ranges).

a lower frequency of left ventricular ejection fraction of less than $50 \%$ than did nonsurviving men with renal injury.

Perioperative complications and operative mortality are listed in Table 4 based on the presence or absence of renal injury for both sexes. With the exception of perioperative myocardial infarction, reported complications were more common in patients with renal injury than in those without such injury, irrespective of sex. In addition, duration of mechanical lung ventilation and duration of intensive care unit hospitalization were longer in patients of both sexes with 
TABLE 2. eGFR (in milliliters per minute per $1.73 \mathrm{~m}^{2}$ ) and the number and percentage of patients with different levels of decreased eGFR and each RIFLE criterion based on patient sex

\begin{tabular}{lcccr}
\hline Parameter & Women & Men & $\begin{array}{c}\chi^{2} \\
\text { test }\end{array}$ & $\begin{array}{c}\boldsymbol{P} \\
\text { value }\end{array}$ \\
\hline Baseline eGFR* & $75.3(57.1-101.5)$ & $81.6(65.3-101.0)$ & NA & .0001 \\
eGFR $<30$ & $154(5.0 \%)$ & $162(2.5 \%)$ & & $\leq .0001$ \\
eGFR 30-60 & $772(25 \%)$ & $1039(16.3 \%)$ & & \\
No renal injury & $2918(94.7 \%)$ & $6119(95.9 \%)$ & 0.3 & \\
RIFLE risk & $50(1.6 \%)$ & $62(1.0 \%)$ & 7.5 & .001 \\
RIFLE injury & $27(0.9 \%)$ & $25(0.4 \%)$ & 8.9 & \\
RIFLE failure & $85(2.8 \%)$ & $175(2.7 \%)$ & 0.0 & \\
\hline
\end{tabular}

The $\chi^{2}$ value for each RIFLE category is provided to indicate the relative weighting of each category for the combined $P$ value. $e G F R$, Estimated glomerular filtration rate; $N A$, not applicable. RIFLE, Risk, Injury, Failure, Loss, and End-Stage Kidney Disease. *Median (interquartile range). RIFLE criteria: risk, eGFR decrease greater than $25 \%$ from baseline; injury, eGFR decrease greater than $50 \%$ from baseline; and failure, acute plasma creatinine level of $350 \mu \mathrm{mol} / \mathrm{L}$ or greater or acute increase of $44 \mu \mathrm{mol} / \mathrm{L}$ or greater after surgical intervention.

renal injury compared with durations in those without this complication. Operative mortality was markedly higher in both women and men with renal injury than in patients who did not have renal injury.

Variables independently associated with renal injury are listed in Table 5. Factors independently associated with renal injury after correction for baseline eGFR are listed in Table 6. Whereas male sex was independently associated with a reduced risk of renal injury in the first model, after correction for baseline eGFR in the second model, patient sex was no longer significantly related to the risk for renal injury. Because of the nonlinear relationship between eGFR and risk for renal injury, these data were splined at a baseline eGFR of $100 \mathrm{~mL} / \mathrm{min}$ per $1.73 \mathrm{~m}^{2}$ of body surface area. A U-shaped relationship between baseline eGFR and risk for renal injury was observed; that is, a reduced risk for renal injury was associated with a baseline eGFR of $100 \mathrm{~mL} / \mathrm{min}$ per $1.73 \mathrm{~m}^{2}$. The risk of renal injury was higher above and below a baseline eGFR of $100 \mathrm{~mL} / \mathrm{min}$ per $1.73 \mathrm{~m}^{2}$.

Independent predictors of operative mortality based on multivariate logistic regression analysis in a model that included both women and men are listed in Table 7. Multiorgan failure was a strong predictor for operative mortality. Renal injury was associated with risk for operative mortality for women and men after adjustment for other variables associated with death.

\section{DISCUSSION}

The data presented here show that the frequency of renal injury is more common in women than in men after cardiac surgery. This risk, however, might be explained in part by women having a lower baseline eGFR than men. In our study patients with renal injury generally had more predisposing risk factors for morbidity and were more likely to have postoperative complications than were those who did not have re- nal injury, regardless of sex. Renal injury was independently associated with operative mortality for women and men.

Women have consistently been shown to have higher operative mortality after cardiac surgery than men due in part to a higher prevalence of risk factors for poor outcomes, including advanced age. ${ }^{1,13-15}$ Nonetheless, in the large multicenter STS database, female sex was reported to be an independent predictor of operative mortality for all but the highest-risk patients. ${ }^{1}$ Our group has reported that a large portion of the excessive risk for operative mortality in women can be explained by a higher prevalence of perioperative stroke in women than in men. ${ }^{13,14}$ The results of the current study now show that renal injury is an additional important determinant for operative mortality in women after cardiac surgery.

Renal insufficiency and renal failure after cardiac surgery are known to be associated with risk for adverse operative outcomes, including in-hospital, short-term, and long-term mortality. ${ }^{2-6}$ Prior studies have reported that women are at higher risk for renal injury after cardiac surgery, but these findings are inconsistent. ${ }^{2,7,16}$ One explanation for why women might have increased susceptibility to postoperative renal injury is that they have a higher prevalence of predisposing risk factors compared with men, including advanced age, diabetes, and hypertension. ${ }^{1,2,13,15}$ Another explanation might be related to the modulating effects of sex hormones on renal physiology and responses to ischemia and reperfusion. ${ }^{17}$ Studies in whole-animal models have demonstrated greater functional and histologic injury from global renal ischemia in male than in female animals, a finding linked to male and female sex steroids. ${ }^{17}$ Whether the absence of estrogens associated with the postmenopausal state modifies these responses is not entirely clear. Nonetheless, in our study we found that after correcting for baseline eGFR, patient sex was no longer significantly associated with renal injury after surgical intervention. Because we found that women had lower eGFRs before surgical intervention than did men, our findings indicate that the higher risk of postoperative renal injury in women is related in part to their lower baseline eGFRs that might, perhaps, contribute to less functional reserve to injury.

Previous investigations that have examined the importance of renal injury on patient outcomes after cardiac surgery have not separately examined whether this risk applies equally to women and men. Rather, most studies have combined data from both sexes, a design that might limit extrapolation of the data to women because they are a minority of cardiac surgical patients. $^{2-6}$ Another disadvantage of the previous studies that might limit comparisons is that they have used multiple definitions for renal injury based on changes in serum creatinine levels. ${ }^{3}$ Serum creatinine levels are influenced by multiple factors in addition to glomerular filtration. ${ }^{8}$ Thus relative, absolute, or both serum creatinine concentrations might poorly predict 
TABLE 3. Distribution of risk factors for operative mortality for patients with and without renal injury based on patient sex

\begin{tabular}{|c|c|c|c|c|c|c|c|c|c|}
\hline Clinical characteristic & $\begin{array}{c}\text { Women, no } \\
\text { renal injury } \\
(n=2959) \\
\end{array}$ & $\begin{array}{l}\text { Women, } \\
\text { renal injury } \\
(\mathbf{n}=\mathbf{1 6 0})\end{array}$ & $\begin{array}{c}\text { Frequency of } \\
\text { variable for } \\
\text { nonsurvivors }\end{array}$ & $\begin{array}{c}P \\
\text { value* }^{*}\end{array}$ & $\begin{array}{c}\text { Men, no } \\
\text { renal injury } \\
(\mathrm{n}=6230)\end{array}$ & $\begin{array}{c}\text { Men, } \\
\text { renal injury } \\
(n=235)\end{array}$ & $\begin{array}{c}\text { Frequency of } \\
\text { variable for } \\
\text { nonsurvivors }\end{array}$ & $\begin{array}{c}P \\
\text { value* }\end{array}$ & $\begin{array}{c}P \\
\text { value } \dagger\end{array}$ \\
\hline Mean \pm SD age (y) & $66.2 \pm 12.3$ & $66.6 \pm 12.5$ & & .688 & $63.7 \pm 11.7$ & $65.9 \pm 12.9$ & & .006 & .7120 \\
\hline African American race & $488(16.5 \%)$ & $39(24.4 \%)$ & $7.4 \%$ & .010 & $603(9.7 \%)$ & $17(9.3 \%)$ & $7.3 \%$ & $<.0001$ & .967 \\
\hline Mean \pm SD BSA $\left(m^{2}\right)$ & $1.8 \pm 0.2$ & $1.8 \pm 0.2$ & & .148 & $2.0 \pm 0.2$ & $2.0 \pm 0.2$ & $2.0 \pm 0.2$ & .687 & .687 \\
\hline Chronic lung disease & $327(11.0 \%)$ & $20(12.5 \%)$ & $5.8 \%$ & .570 & $532(8.6 \%)$ & $33(18.1 \%)$ & $6.0 \%$ & .002 & .885 \\
\hline Diabetes & $921(31.1 \%)$ & $58(36.2 \%)$ & $5.9 \%$ & .174 & $1553(25.0 \%)$ & $53(29.1 \%)$ & $4.6 \%$ & .015 & .141 \\
\hline Left ventricular EF $<50 \%$ & $1501(50.7 \%)$ & $98(61.2 \%)$ & $6.12 \%$ & .009 & $3578(57.7 \%)$ & $123(67.6 \%)$ & $13.7 \%$ & .582 & $<.0001$ \\
\hline Left ventricular EF $<30 \%$ & $333(11.2 \%)$ & $33(20.6 \%)$ & $9.06 \%$ & $<.001$ & $856(13.8 \%)$ & $56(30.8 \%)$ & $5.0 \%$ & .018 & .006 \\
\hline Reoperation & $114(3.8 \%)$ & $19(11.9 \%)$ & $14.3 \%$ & $<.001$ & $165(2.7 \%)$ & $15(8.2 \%)$ & $8.6 \%$ & $<.0001$ & .106 \\
\hline Hypercholesterolemia & $1567(53.0 \%)$ & $77(48.1 \%)$ & $4.7 \%$ & .233 & $3474(56.0 \%)$ & $75(41.2 \%)$ & $2.9 \%$ & $<.0001$ & .001 \\
\hline Hypertension & $1995(67.4 \%)$ & $122(76.2 \%)$ & $5.8 \%$ & .020 & $3991(64.1 \%)$ & $167(71.1 \%)$ & $4.0 \%$ & .028 & .002 \\
\hline \multicolumn{10}{|l|}{ IABP } \\
\hline Preoperative & $125(4.2 \%)$ & $13(8.1 \%)$ & $9.4 \%$ & .017 & $228(3.7 \%)$ & $25(10.6 \%)$ & $9.9 \%$ & .116 & .883 \\
\hline Intraoperative & $59(2.0 \%)$ & $13(8.1 \%)$ & $18.1 \%$ & & $17(0.3 \%)$ & $1(0.4 \%)$ & $5.6 \%$ & & .784 \\
\hline Postoperative & $10(0.3 \%)$ & $5(3.1 \%)$ & $33.3 \%$ & & $106(45.1 \%)$ & $21(8.9 \%)$ & $3.3 \%$ & & .784 \\
\hline Myocardial infarction & $1217(41.1 \%)$ & $60(37.5 \%)$ & $4.7 \%$ & .363 & $2849(46.0 \%)$ & $94(51.6 \%)$ & $3.3 \%$ & .232 & .032 \\
\hline Emergency PCI & $58(2.0 \%)$ & $2(1.0 \%)$ & $3.3 \%$ & .320 & $111(1.8 \%)$ & $4(2.2 \%)$ & $1.7 \%$ & .372 & .608 \\
\hline PVD & $448(15.1 \%)$ & $29(1.8 \%)$ & $6.1 \%$ & .307 & $740(11.9 \%)$ & $39(21.4 \%)$ & $5.0 \%$ & .032 & .402 \\
\hline Cerebral vascular disease & $381(12.9 \%)$ & $25(15.6 \%)$ & $6.2 \%$ & .314 & $599(9.7 \%)$ & $34(18.7 \%)$ & $4.4 \%$ & .284 & .204 \\
\hline Cardiogenic shock & $22(0.7 \%)$ & $1(0.6 \%)$ & $4.3 \%$ & .865 & $39(0.6 \%)$ & $4(2.2 \%)$ & $13.6 \%$ & & .408 \\
\hline Current smoker & $383(12.9 \%)$ & $16(10.0 \%)$ & $4.0 \%$ & .278 & $827(13.3 \%)$ & $15(8.2 \%)$ & $3.5 \%$ & & .668 \\
\hline Triple-vessel disease & $1271(42.9 \%)$ & $52(32.5 \%)$ & $3.9 \%$ & .274 & $3531(57.0 \%)$ & $87(47.8 \%)$ & $2.7 \%$ & & .030 \\
\hline $\begin{array}{l}\text { Left main } \\
\qquad \text { stenosis }>50 \%\end{array}$ & $261(8.8 \%)$ & $14(8.7 \%)$ & $5.1 \%$ & .524 & $607(9.8 \%)$ & $17(9.3 \%)$ & $2.2 \%$ & & .022 \\
\hline \multicolumn{10}{|l|}{ Type of operation } \\
\hline CABG only & & & & .003 & & & & & \\
\hline With CPB & $1991(67.3 \%)$ & $86(53.7 \%)$ & $4.1 \%$ & $<.0001$ & $4808(77.6 \%)$ & $132(72.5 \%)$ & $2.9 \%$ & $<.0001$ & .008 \\
\hline Without CPB & $93(3.1 \%)$ & $7(4.4 \%)$ & $7.0 \%$ & & $214(3.4 \%)$ & $5(2.7 \%)$ & $5.9 \%$ & & \\
\hline \multicolumn{10}{|l|}{ AVR } \\
\hline Repair & $120(4.0 \%)$ & $3(1.9 \%)$ & $2.4 \%$ & $<.0001$ & $304(4.9 \%)$ & $7(3.8 \%)$ & $6.1 \%$ & $<.0001$ & .804 \\
\hline Replacement & $573(19.4 \%)$ & $53(33.1 \%)$ & $8.5 \%$ & & $981(15.8 \%)$ & $48(26.4 \%)$ & $6.0 \%$ & & \\
\hline \multicolumn{10}{|l|}{ MVR } \\
\hline Repair & $147(5.0 \%)$ & $9(5.6 \%)$ & $5.8 \%$ & .004 & $256(4.1 \%)$ & $8(4.4 \%)$ & $3.0 \%$ & $<.0001$ & .147 \\
\hline Replacement & $462(15.6 \%)$ & $49(30.6 \%)$ & $9.6 \%$ & $<.0001$ & $357(5.8 \%)$ & $22(12.1 \%)$ & $8.7 \%$ & & \\
\hline CABG/AVR & $247(8.3 \%)$ & $24(15.0 \%)$ & $8.9 \%$ & & $482(7.8 \%)$ & $27(14.8 \%)$ & $7.4 \%$ & $<.001$ & .057 \\
\hline CABG/MVR & $164(5.5 \%)$ & $20(12.5 \%)$ & $21.9 \%$ & & $210(3.4 \%)$ & $16(8.8 \%)$ & $4.9 \%$ & .345 & .169 \\
\hline $\begin{array}{l}\text { Duration aortic } \\
\quad \text { crossclamp }(\mathrm{min}) \ddagger\end{array}$ & $72(55-96)$ & $85(62-113)$ & & .0005 & 75 (58-97) & $86(59-118)$ & & $<.0001$ & .816 \\
\hline Duration of CPB (min) $\ddagger$ & $109(86-139)$ & $138(104-177)$ & & .0001 & $111(89-138)$ & $129(100-186)$ & & .0001 & .461 \\
\hline
\end{tabular}

Values are reported as numbers of patients, with percentages in parentheses for the variable for each column of survivors or nonsurvivors. A separate column of percentages lists the frequency of the variable for patients without renal injury for each sex. $S D$, Standard deviation; $B S A$, body surface area; $E F$, ejection fraction; $I A B P$, intra-aortic balloon pump; $P C I$, percutaneous coronary artery intervention; $P V D$, peripheral vascular disease; $C A B G$, coronary artery bypass graft; $C P B$, cardiopulmonary bypass; $A V R$, aortic valve replacement; $M V R$, mitral valve replacement. $* P$ value for comparison between survivors and nonsurvivors of the same sex. $\dagger P$ value for comparison of the distribution of the variable between women and men. $\ddagger$ Values are reported as medians (interquartile ranges).

renal function in elderly women. In this study we estimated eGFR with the Modification of Diet in Renal Disease equations, which take into account age, sex, and race. ${ }^{10,11}$ Furthermore, we used RIFLE criteria for defining grades of renal injury. ${ }^{12}$ Regardless, the frequency of renal injury and the associated mortality in our study were similar to those of other studies. ${ }^{2-6,18-20}$

Renal injury associated with cardiac surgery likely results from hypotension, embolism, or exposure to nephrotoxins, including radiocontrast dye used before surgical interven- tion. $^{4,21,22}$ Patients with renal injury are more likely than others to have postoperative complications. The development of complications, such as sepsis and other organ injury, might predispose them to hemodynamic instability and renal ischemia, as well as to exposure to nephrotoxic antibiotics. Nonsurgical patients with renal injury have prothrombotic tendency, endothelial dysfunction, and other abnormalities that predispose them to cardiovascular disease. ${ }^{23}$ Perhaps these variables contribute to the poorer outcomes seen in patients with renal injury after cardiac surgery. In our study we 
TABLE 4. Variables independently associated with renal injury based on multivariate logistic regression analysis

\begin{tabular}{lcc}
\hline \multicolumn{1}{c}{ Variable } & Odds ratio $(\mathbf{9 5} \% \mathbf{C I})$ & $\boldsymbol{P}$ value \\
\hline Multiorgan failure & $14.44(8.57-24.33)$ & $\leq .0001$ \\
African American race & $1.83(1.39-2.42)$ & $\leq .0001$ \\
Duration of cardiopulmonary & $1.01(1.01-1.02)$ & $\leq .0001$ \\
$\quad$ bypass & $0.68(0.54-0.85)$ & .001 \\
Male sex & $1.50(1.17-1.93)$ & .002 \\
Hypertension & $1.48(1.11-1.96)$ & .007 \\
Left ventricular & & \\
$\quad$ ejection fraction $<30 \%$ & $0.77(0.61-0.96)$ & .021 \\
Hypercholesterolemia & &
\end{tabular}

CI, Confidence interval.

observed an apparent U-shaped relationship between baseline eGFR values and risk for renal injury after surgical intervention. At less than a baseline of $100 \mathrm{~mL} / \mathrm{min}$ per $1.73 \mathrm{~m}^{2}$ of body surface area, each unit increase in eGFR reduced the risk for renal injury. In contrast, for patients with baseline eGFRs of greater than $100 \mathrm{~mL} / \mathrm{min}$ per $1.73 \mathrm{~m}^{2}$ of body surface area, each unit increase in eGFR increased the risk for renal injury. Reasons for the latter observation are not clear other than the potential for higher renal embolic load during surgical intervention for patients with high baseline eGFRs. Importantly, our observations suggest that optimizing the eGFR before surgical intervention in patients with a baseline eGFR of up to $100 \mathrm{~mL} / \mathrm{min}$ per $1.73 \mathrm{~m}^{2}$ of body surface area might provide a strategy for reducing the risk for renal injury, particularly in women. One potential strategy would be to allow recovery of renal function from radiocontrast dye exposure before subjecting patients to the added risk of renal injury for surgical perturbations.

Many of the variables that we identified to be independently associated with mortality are widely recognized. ${ }^{1}$ Women are likely to be older than men at the time of surgical intervention and are more likely to have hypertension, fewer coronary artery stenoses, and preserved left ventricular function. ${ }^{1}$ Thus differences in preoperative comorbidities between patient sexes might confound our examination of
TABLE 5. Variables independently associated with renal injury

\begin{tabular}{lcc}
\hline \multicolumn{1}{c}{ Variable } & Odds ratio $(\mathbf{9 5} \%$ CI) & $\boldsymbol{P}$ value \\
\hline Multiorgan failure & $12.65(7.00-22.87)$ & $\leq .0001$ \\
African American race & $1.80(1.32-2.44)$ & $\leq .0001$ \\
$\begin{array}{l}\text { Duration of cardiopulmonary } \\
\text { bypass }\end{array}$ & $1.01(1.005-1.01)$ & $\leq .0001$ \\
$\begin{array}{l}\text { Baseline eGFR }<100 \mathrm{~mL} / \mathrm{min} \\
\text { per } 1.73 \mathrm{~m}^{2 *}\end{array}$ & $0.94(0.94-0.95)$ & $\leq .0001$ \\
$\begin{array}{l}\text { Baseline } \mathrm{eGFR} \geq 100 \mathrm{~mL} / \mathrm{min} \\
\text { per } 1.73 \mathrm{~m}^{2} \dagger\end{array}$ & $1.08(1.07-1.10)$ & $\leq .0001$ \\
\hline
\end{tabular}

Calculations are based on multivariate logistic regression analysis after adjusting for baseline estimated glomerular filtration rate with a linear spline at $100 \mathrm{~mL} / \mathrm{min}$ per $1.73 \mathrm{~m}^{2}$. CI, Confidence interval; $e G F R$, estimated glomerular filtration rate. *The risk for each 1-unit increase in eGFR when baseline eGFR is less than $100 \mathrm{~mL} / \mathrm{min}$ per $1.73 \mathrm{~m}^{2}$ of body surface area. $\dagger$ The risk for a 1 -unit increase in eGFR when baseline eGFR is greater than $100 \mathrm{~mL} / \mathrm{min}$ per $1.73 \mathrm{~m}^{2}$ of body surface area.

the importance of renal injury for operative mortality. Nonetheless, most of these risk factors for mortality were similar between patient sexes based on univariate analysis, although several variables did differ between survivors and nonsurvivors in analysis within each sex. However, our use of multivariate logistic regression analysis to adjust for other potential confounding factors between the sexes suggests that a higher comorbidity rate in women with renal injury is an unlikely explanation for the link between this outcome and operative mortality. We observed that hypercholesterolemia was associated with lower mortality risk in men. This finding might represent an epiphenomenon that identifies patients receiving statin drugs, which have been shown to be associated with a decreased risk for mortality after cardiac surgery. ${ }^{24}$ However, whether preoperative statin therapy decreases the risk of postoperative acute kidney injury is not conclusive. ${ }^{24,25}$

In addition to the retrospective nature of this analysis, several limitations are associated with this study. Our analysis included a heterogeneous population of patients undergoing CABG surgery, valvular surgery, or both. Serum creatinine levels, which were used in the definition of renal injury, might have been influenced by nonrenal factors, including

TABLE 6. Postoperative complications and outcomes

\begin{tabular}{|c|c|c|c|c|c|c|}
\hline \multirow[b]{2}{*}{ Clinical characteristic } & \multicolumn{3}{|c|}{ Women } & \multicolumn{3}{|c|}{ Men } \\
\hline & $\begin{array}{c}\text { No renal } \\
\text { injury }(n=2920) \\
\end{array}$ & $\begin{array}{c}\text { Renal } \\
\text { Injury }(n=160)\end{array}$ & $P$ value & $\begin{array}{c}\text { No renal } \\
\text { Injury }(n=6146) \\
\end{array}$ & $\begin{array}{c}\text { Renal } \\
\text { Injury }(\mathbf{n}=\mathbf{2 3 5})\end{array}$ & $P$ value \\
\hline Reoperation for bleeding & $41(1.4 \%)$ & $9(5.6 \%)$ & $<.0001$ & $91(1.5 \%)$ & $17(7.2 \%)$ & $<.0001$ \\
\hline Stroke & $158(5.3 \%)$ & $23(14.4 \%)$ & $<.0001$ & $212(3.4 \%)$ & $24(10.2 \%)$ & $<.0001$ \\
\hline Perioperative MI & $10(0.3 \%)$ & 0 & .453 & $19(0.3 \%)$ & $2(0.8 \%)$ & .160 \\
\hline Pneumonia & $77(2.6 \%)$ & $12(7.5 \%)$ & $<.0001$ & $170(2.7 \%)$ & $29(12.3 \%)$ & $<.0001$ \\
\hline Sepsis & $43(1.4 \%)$ & $28(17.5 \%)$ & $<.0001$ & $72(1.1 \%)$ & $38(16.2 \%)$ & $<.0001$ \\
\hline Multiorgan failure & $17(0.6 \%)$ & $10(6.2 \%)$ & $<.0001$ & $28(0.4 \%)$ & $25(11.9 \%)$ & $<.0001$ \\
\hline Duration in the ICU (h) & $48(24-96)$ & $191(84-456)$ & .0001 & $36(22-69)$ & $165(73-449)$ & .0001 \\
\hline $\begin{array}{r}\text { Duration of lung } \\
\text { ventilation }(\mathrm{h})\end{array}$ & $13(9-22)$ & $110(30-268)$ & .0001 & $10(7-16)$ & $63(14-281)$ & $<.0001$ \\
\hline Operative mortality & $96(3.2 \%)$ & $33(20.6 \%)$ & $<.0001$ & $139(2.2 \%)$ & $43(18.3 \%)$ & $<.0001$ \\
\hline
\end{tabular}

$M I$, Myocardial infarction; $I C U$, intensive care unit. 
TABLE 7. Variables independently associated with mortality after cardiac surgery based on multivariate logistic regression analysis

\begin{tabular}{lcc}
\hline \multicolumn{1}{c}{ Variable } & Odds ratio $(\mathbf{9 5} \%$ CI) & $\boldsymbol{P}$ value \\
\hline Multiorgan failure & $31.57(16.23-63.39)$ & $\leq .0001$ \\
Reoperation for bleeding & $3.98(2.22-7.13)$ & $\leq .0001$ \\
Male subject with renal injury & $3.72(2.21-6.23)$ & $\leq .0001$ \\
Female subjects with renal injury & $3.77(2.18-6.54)$ & $\leq .0001$ \\
Stroke & $3.60(2.49-5.22)$ & $\leq .0001$ \\
Left ventricular ejection fraction $<30 \%$ & $2.05(1.50-2.82)$ & $\leq .0001$ \\
Duration of cardiopulmonary bypass & $1.01(1.01-1.02)$ & $\leq .0001$ \\
Duration of aortic crossclamping & $0.99(0.98-0.99)$ & $\leq .0001$ \\
Hypercholesterolemia & $0.75(0.57-0.94)$ & .042 \\
\hline
\end{tabular}

CI, Confidence interval.

body weight, ethnicity, sex, and nutrition. ${ }^{1,8}$ Cystatin $\mathrm{C}$ is an endogenous marker of renal function that is more sensitive than creatinine for identifying mild and moderate decrements in eGFR. ${ }^{26}$ Although use of the latter marker might have provided a more accurate detection of mild renal injury, it was not widely available or routinely measured during the period of this study. Likewise, aprotinin use, a variable found in retrospective studies to be associated with renal injury, was not recorded in our database. ${ }^{27}$ Antifibrinolytic drugs consisted of aminocaproic acid; aprotinin was mostly restricted to reoperative surgery. Whether inclusion of aprotonin in our multivariate models of operative mortality would have modified our finding that renal injury is independently associated with operative mortality in women and men is not known but unlikely because only a minority of patients received the drug.

In summary, we have shown that the occurrence of renal injury after cardiac surgery is independently associated with an increased risk of postoperative mortality. Furthermore, the incidence of renal injury after cardiac surgery appears to be higher in women than in men. However, this discrepancy could be caused in part by women having a lower baseline eGFR than men. Optimizing eGFR before surgical intervention in patients with a baseline eGFR of less than $100 \mathrm{~mL} / \mathrm{min}$ per $1.73 \mathrm{~m}^{2}$ of body surface area and allowing patients time to recover renal function after exposure to renal toxins, such as radiocontrast dye, might provide strategies for reducing the risk of renal injury after cardiac surgery.

\section{References}

1. Edwards F, Carey J, Grover F, Bero J, Hartz R. Impact of gender on coronary bypass operative mortality. Ann Thorac Surg. 1998;66:125-31.

2. Mangano CM, Diamondstone L, Ramsay J, Aggarwal A, Herskowitz A, Mangano DT. Renal dysfunction after myocardial revascularization: risk factors, adverse outcomes, and hospital resource utilization. The Multicenter Study of Perioperative Ischemia Research Group. Ann Intern Med. 1998;128:194-203.

3. Loef BG, Epema AH, Smilde TD, Henning R, Ebels T, Navis G, et al. Immediate postoperative renal function deterioration in cardiac surgical patients predicts inhospital mortality and long-term survival. J Am Soc Nephrol. 2005;16:195-200.

4. Brown JR, Cochran RP, Dacey LJ, Ross CS, Kunzelman KS, Dunton RF, et al. Perioperative increases in serum creatinine are predictive of increased 90-day mortality after coronary artery bypass graft surgery. Circulation. 2006; 114(suppl):I409-13
5. Brown J, Cochran R, MacKenzie T, Furnary A, Kunzelman K, Ross C, et al. Long-term survival after cardiac surgery is predicted by estimated glomerular filtration rate. Ann Thorac Surg. 2008;86:4-11.

6. Lassnigg A, Schmid ER, Hiesmayr M, Falk C, Druml W, Bauer P, et al. Impact of minimal increases in serum creatinine on outcome in patients after cardiothoracic surgery: do we have to revise current definitions of acute renal failure? Crit Care Med. 2008;36:1129-37.

7. Brown J, Cochran R, Leavitt B, Dacey L, Ross C, MacKenzie T, et al. Multivariable prediction of renal insufficiency developing after cardiac surgery. Circulation. 2007;116(suppl I):I139-43.

8. Duncan L, Heathcote J, Djurdjev O, Levin A. Screening for renal disease using serum creatinine: who are we missing? Nephrol Dial Transplant. 2001;16:1042-6.

9. Edwards F, Carey J, Grover F, Bero J, Hartz RS. Impact of gender on coronary bypass operative mortality. Ann Thorac Surg. 1998;66:125-31.

10. Myers G, Miller W, Coresh J, Fleming J, Greenberg N, Greene T, et al. Recommendations for improving serum creatinine measurement: a report from the Laboratory Working Group of the National Kidney Disease Education Program. Clin Chem. 2006;52:5-18.

11. Levey A, Coresh J, Greene T, Marsh J, Stevens L, Kusek J, et al. Expressing the Modification of Diet in Renal disease study equation for estimating glomerular filtration rate with standardized serum creatinine values. Clin Chem. 2007;53:766-72.

12. Kuitunen A, Vento A, Suojaranta-Ylinen R, Pettilä V. Acute renal failure after cardiac surgery: evaluation of the RIFLE classification. Ann Thorac Surg. 2006;81:542-6.

13. Hogue C Jr, Barzilai B, Pieper K, Coombs L, DeLong E, Kouchoukos N, et al. Sex differences in neurological outcomes and mortality after cardiac surgery: a society of thoracic surgery national database report. Circulation. 2001;103:2133-7.

14. Hogue C Jr, Sundt T, Barzilai B, Schecthman K, Dávila-Román V. Cardiac and neurologic complications identify risks for mortality for both men and women undergoing coronary artery bypass graft surgery. Anesthesiology. 2001;95:1074-8.

15. Koch C, Weng Y, Zhou S, Savino J, Mathew J, Hsu P, et al. Prevalence of risk factors, and not gender per se, determines short- and long-term survival after coronary artery bypass surgery. J Cardiothorac Vasc Anesth. 2003;17:585-93.

16. Thakar C, Liangos O, Yared J, Nelson D, Piedmonte M, Hariachar S, et al. ARF after open-heart surgery: influence of gender and race. Am J Kidney Dis. 2003;41: 742-51.

17. Hutchens M, Dunlap J, Hurn P, Jarnberg P. Renal ischemia: does sex matter? Anesth Analg. 2008;107:239-49.

18. Chertow GM, Levy EM, Hammermeister KE, Grover F, Daley J. Independen association between acute renal failure and mortality following cardiac surgery. Am J Med. 1998;104:343-8.

19. Conlon PJ, Stafford-Smith M, White WD, Newman MF, King S, Winn MP, et al Acute renal failure following cardiac surgery. Nephrol Dial Transplant. 1999;14: 1158-62.

20. Mehta R, Grab J, O’Brien S, Bridges C, Gammie J, Haan C, et al. Bedside tool for predicting the risk of postoperative dialysis in patients undergoing cardiac surgery. Circulation. 2006;114:2208-16.

21. Nally JJ. Acute renal failure in hospitalized patients. Cleve Clin J Med. 2002;69: 569-74.

22. Dávila-Román V, Kouchoukos N, Schechtman K, Barzilai B. Atherosclerosis of the ascending aorta is a predictor of renal dysfunction after cardiac operations. J Thorac Cardiovasc Surg. 1999;117:111-6.

23. Sarnak M, Levey A, Schoolwerth A, Coresh J, Culleton B, Hamm L, et al. Kidney disease as a risk factor for development of cardiovascular disease: a statement from the American Heart Association Councils on Kidney in Cardiovascular Disease, High Blood Pressure Research, Clinical Cardiology, and Epidemiology and Prevention. Hypertension. 2003;42:1050-65.

24. Liakopoulos O, Choi Y, Haldenwang P, Strauch J, Wittwer T, Dorge H, et al Impact of preoperative statin therapy on adverse postoperative outcomes in patients undergoing cardiac surgery: a meta-analysis of over 30000 patients. Eur Heart J. 2008;29:1548-59.

25. Huffmyer J, Mauermann W, Thiele R, Ma J, Nemergut E. Preoperative statin administration is associated with lower mortality and decreased need for postoperative hemodialysis in patients undergoing coronary artery bypass graft surgery. J Cardiothorac Vasc Anesth. 2009;23:468-73.

26. Newman D, Thakkar H, Edwards R, Wilkie M, White T, Grubb A, et al. Serum cystatin $\mathrm{C}$ measured by automated immunoassay: a more sensitive marker of changes in GFR than serum creatinine. Kidney Int. 1995;47:312-8.

27. Karkouti K, Beattie W, Dattilo K, McCluskey S, Ghannam M, Hamdy A, et al A propensity score case-control comparison of aprotinin and tranexamic acid in high-transfusion-risk cardiac surgery. Transfusion. 2006;46:327-38. 